\title{
A ARGENTINA EM DOIS TEMPOS DA CONVERSIBILIDADE À REESTRUTURAÇÃo DA DÍVIDA*
}

\author{
André Moreira Cunha ${ }^{* *}$
}

\author{
Andrés Ferrari ${ }^{* *}$
}

RESUMO Em poucos anos a Argentina passou de show-case dos defensores das reformas liberalizantes na América Latina à condição de pária dos mercados financeiros internacionais. Depois de uma década de adoção de um regime de câmbio fixo e de adesão irrestrita à agenda de reformas do Consenso de Washington, o país mergulhou em uma profunda crise econômica e social. O presente artigo tem por objetivo analisar as origens e os desdobramentos dessa crise, dos quais o episódio mais recente foi o processo de reestruturação da dívida externa. Argumentamos que, mesmo com o aparente sucesso do mega-swap, o país ainda terá um longo caminho a percorrer para digerir a herança dos anos da conversibilidade.

Palavras-chave: Argentina; reestruturação de dívidas; desenvolvimento

Código JEL: F34, O11

\footnotetext{
*Artigo recebido em 30 de maio de 2005 e aprovado para publicação em 2 de maio de 2006. Versão atualizada em junho de 2005 do trabalho apresentado no X Encontro Nacional de Economia Política, realizado em Campinas, SP. Os autores agradecem o apoio de pesquisa do bolsista Pibic-CNPq, Henrique Renck.

** Professor do Departamento de Economia da UFRGS e pesquisador do CNPq, e-mail: amcunha@ hotmail.com

*** Doutorando em Economia na UFRGS e bolsista do CNPq, e-mail: andres@ppgel.ppge.ufrgs.br ou ferrariandres@yahoo.com
} 


\section{ARGENTINA IN TWO MOMENTS: FROM CONVERTIBILITY TO DEBT RESTRUCTURING}

ABSTRACT In a few years Argentina changed its position from liberalization showcase in Latin America to pariah in international financial markets. After one decade of fixed exchange rate regime and implementation of Washington Consensus reforms agenda, the country experienced a deep economic and social crisis. This paper analyzes origins and consequences of the Argentinean crisis. We argue that despite the recent success in the mega-swap, the country will face a long way to recover the negative heritage of the "Convertibilidad" period.

Key words: Argentine; debt restructuring; development 


\section{INTRODUÇÃO}

Em poucos anos a Argentina passou de show-case dos defensores das reformas liberalizantes na América Latina à condição de pária dos mercados financeiros internacionais. Depois de uma década de adoção de um regime de câmbio fixo, a assim chamada "conversibilidade", onde o valor do peso com respeito ao dólar norte-americano foi estabelecido por meio de uma emenda constitucional, o país experimentou, entre 2001 e 2002, uma séria crise financeira, que aprofundou um quadro de degradação econômica e social que já vigorava no país. A euforia dos anos da nova plata dulce ${ }^{1}$ deixou por herança uma elevada dívida externa, cuja reestruturação em 2005 parece ser um dos maiores casos de deságio registrados na história recente das finanças internacionais. Ainda que o governo argentino comemore a recente recuperação da economia e a "vitória" na longa queda-de-braço com seus credores, o fato é que a digestão dos passivos externo (e fiscal) e social ainda demandará um enorme esforço, tanto para o setor público quanto para a sociedade.

Nesse contexto, o presente artigo tem por objetivo analisar as principais características dessa crise financeira e da reestruturação da dívida argentina. Buscamos, em um primeiro momento, resgatar as raízes recentes do processo social, político e econômico que deu sustentação ao que pode parecer, à primeira vista, um paradoxo, qual seja: o fato de que a conversibilidade esteve na base da deterioração econômica e social do país, sem que isso se traduzisse em perda de apoio político. Estabeleceu-se uma solidariedade em torno de sua defesa, na medida em que crescia a dolarização dos passivos e ativos dos agentes econômicos. Isso criou uma certa inércia social, cujos sintomas mais aparentes podem ser buscados, por exemplo, no fato de que parte expressiva da sociedade e da intelectualidade do país não era capaz de associar a crise econômica e social ao modelo econômico subjacente à conversibilidade. Tanto é verdade que o projeto liberal de Menem ${ }^{2}$ foi consagrado com sua reeleição. Ademais, no processo de sua sucessão, nenhum dos principais candidatos se opôs ao peso forte. Da mesma forma, a conversibilidade caiu mais pelo efeito de suas fragilidades do que por uma decisão política baseada em uma crítica teórica consistente ou com a apresentação de um modelo alternativo de estabilização e desenvolvimento. Depois disso, analisamos a crise financeira e o processo de reestruturação da dívida. Este 
segundo se dá em um momento de recuperação econômica que, por sua vez, deve ser entendida a partir do resgate da competitividade do peso e do ciclo internacional excepcionalmente favorável, que combina a elevação nos preços de commodities agrícolas e minerais, centrais para a sua economia, um maior crescimento do comércio e da renda na economia internacional e a melhoria dos níveis de liquidez financeira nos mercados internacionais. Nas nossas considerações finais procuramos, ainda em caráter especulativo, identificar alguns dos desafios que se colocam para o país de agora em diante. Estaríamos diante de uma real mudança de postura em face dos interesses do sistema financeiro internacional? Ou, alternativamente, estamos apenas assistindo aos desdobramentos de mais um episódio dos recorrentes ciclos de liquidez financeira externa, seguidos de euforia especulativa e crise financeira, tão comuns nos países periféricos em geral ${ }^{3}$ e na Argentina em particular?

\section{DE MENEM A KIRCHNER, DA CONVERSIBILIDADE AO CORRALITO}

Para compreender o contexto social, econômico e político que criou as condições para que o processo de reestruturação da dívida tivesse o desfecho ora visto, há que se resgatar a trajetória recente da Argentina, marcada por um mergulho profundo nas reformas liberalizantes derivadas do receituário do Consenso de Washington. ${ }^{4}$ Por um lado, os primeiros anos da "conversibilidade" são de elevado dinamismo em termos de crescimento da renda (gráficos 1 e 2$)^{5}$ e sucesso no combate à inflação crônica (gráfico 3 ). Por

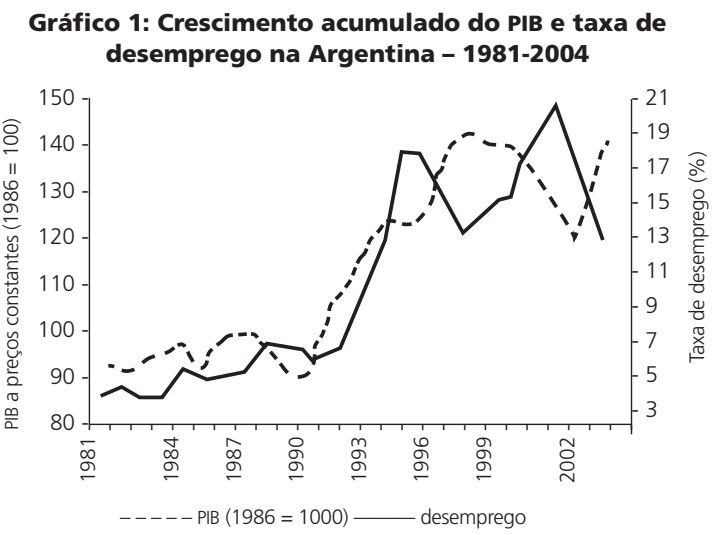




\section{Gráfico 2: Evolução do PIB per capita e do consumo das famílias na Argentina - 1981-2004 (1986 = 100)}

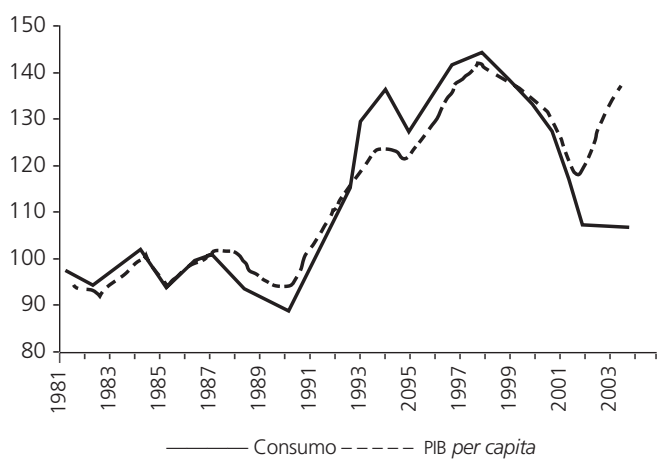

Fonte: Anuário Estatístico da Cepal, 2003 (www.eclac.cl). Dados capturados em março de 2005. Elaborado pelos autores.

\section{Gráfico 3: inflação na Argentina - 1980-1991 (\% a.a.)}

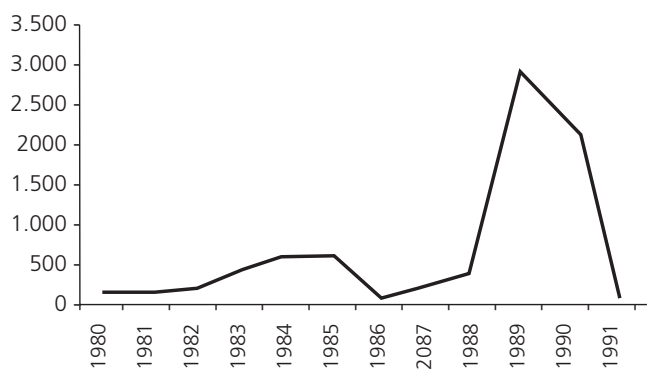

(continuação) - 1992-2004 (\% a.a.)

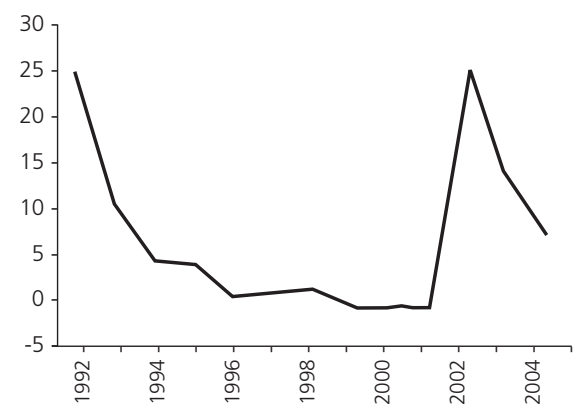

Fonte: IMF World Economic Otlook Database, september 2004 (www.imf.org). Dados capturados em março de 2005. Elaborado pelos autores. 
outro, na segunda metade dos anos 1990, verificou-se um quadro agudo de deterioração social. A taxa de desemprego triplicou em face da média da "década perdida" e os salários reais atingiram os piores níveis das últimas três décadas (gráfico 7). Ampliou-se, de forma inédita na história argentina recente e em um ritmo talvez sem precedentes no próprio contexto latinoamericano, o grau de desigualdade na distribuição de renda (tabela 1). Se, no início dos anos 1990, o país apresentava índices de concentração bem melhores do que a média do continente, em 2002 a situação só não era pior que a do Brasil, que há muito tempo figura entre os piores perfis distributivos do planeta. Assim, não é possível pensar a Argentina contemporânea sem se perceber que o país experimentou uma profunda alteração em sua estrutura social. Apesar de não termos o objetivo de explorar aqui as diversas implicações desse fato, consideramos essencial partir dele para avançar na nossa análise.

Nos anos 1990, a Argentina era tida por muitos como um caso exemplar de sucesso na adoção de um regime cambial duro, o currency board (CB), como forma de combate à inflação e, assim, de resgate da credibilidade das autoridades monetárias em países que haviam experimentado processos inflacionários crônicos. Analistas respeitados como John Williamson (1995), o idealizador da expressão Consenso de Washington, e Robert Mundell (2000), dentre outros, garantiam o respaldo intelectual ao modelo argentino. O CB foi implementado em 1991, a partir do Plano de Conversibilidade. A Argentina havia experimentado ao longo da "década perdida" um processo de baixo crescimento (gráficos 1 e 2) e elevada inflação (gráfico 3). Em 1988,

Tabela 1: Distribuição de renda em países e anos selecionados (\% do total)

\begin{tabular}{llllllll}
\hline \multicolumn{2}{c}{$10-$} & \multicolumn{2}{c}{$10+$} & & $10-$ & $10+$ \\
\hline 1. Argentina & 1980 & 2,8 & 30,9 & 4. Chile & 1990 & 1,7 & 39,2 \\
\hline & 1990 & 2,3 & 34,8 & & 1998 & 1,7 & 39,1 \\
\hline 2. Bolívia & 2002 & 1,8 & 40,7 & & 2000 & 1,8 & 39,7 \\
\hline & 1989 & 0,7 & 38,2 & 5. Ecuador & 1990 & 2,1 & 30,5 \\
\hline 3. Brasil & 1994 & 2,0 & 35,6 & & 1997 & 2,3 & 31,9 \\
\hline & 2002 & 1,7 & 38,4 & & 2002 & 1,8 & 34,3 \\
\hline & 1990 & 1,1 & 41,8 & 6. México & 1984 & 3,2 & 25,8 \\
\hline
\end{tabular}

Fonte: Anuário Estatístico da Cepal, 2003 (www.eclac.cl). 
o país havia suspendido o pagamento da dívida externa. No ano seguinte, o novo presidente, Carlos Menem, assume o cargo de forma antecipada, após a fragilização do governo Alfonsín, que enfrentou dois episódios hiperinflacionários. Na ocasião, as reservas internacionais do Banco Central estavam abaixo dos US\$ 500 milhões e a inflação anualizada beirava os 5.000\%.

Em 1991, o ministro da Economia, Domingos Cavallo, lançou o Plano de Conversibilidade, também conhecido por Plano Cavallo. Fixouse o valor do peso em termos da moeda norte-americana na proporção ${ }^{6}$ 10.000 austrais (A) por dólar. Com a troca do austral pelo peso na relação ${ }^{7}$ A $10.000=\$ 1$, surgiu a politicamente conveniente igualdade " 1 por 1" entre o peso e o dólar, cujo impacto psicológico não pode ser negligenciado. Além disso, determinou-se que $80 \%$ dos pesos em circulação deveriam estar lastreados nas reservas internacionais. Tal restrição era aliviada pela expansão da dívida pública denominada em dólares, que poderia lastrear a expansão monetária em pesos. Em momentos de aperto de liquidez externa, como em 1995 - por efeito da crise mexicana —, tal mecanismo funcionava como amortecedor para a manutenção da liquidez doméstica. Por fim, proibiu-se a utilização de indexadores nos contratos, de modo a quebrar a inércia inflacionária, e limitou-se fortemente a capacidade do Banco Central de emprestar para o governo e o setor financeiro. No ano seguinte, implementou-se a independência do Banco Central que, a partir de então, passou a adotar novas regras de supervisão bancária, muitas das quais mais rígidas do que as definidas no Acordo da Basiléia (Carrera, s.d.; Calvo e Tavi, 2005; IMF, 2004, 2004b).

O sistema de conversibilidade revelou uma baixa capacidade de absorver os choques externos. Ademais, induziu a cristalização de um padrão de crescimento baseado na expansão do consumo privado em um ritmo superior à variação da renda (gráfico 2), financiado com crescente endividamento externo. Os níveis de investimento não cresceram proporcionalmente ao boom de entrada de poupança externa. ${ }^{8}$ Tal quadro foi agravado pela deterioração da posição comercial externa e pela desestruturação do setor produtivo. Os crescentes déficits em conta corrente, que ultrapassavam a casa dos $4 \%$ do PIB, traduziam a expansão nos gastos com bens e serviços do resto do mundo em uma proporção muito maior do que a capacidade de o país adquirir divisas por meio das exportações. A entrada líquida de capitais 
pela via financeira permitiu a sustentação desse modelo, o que implicou um endividamento crescente ${ }^{9}$ que fez com que (i) a conta de juros mais do que triplicasse sua participação no total dos gastos públicos, dado que a dívida externa era predominantemente pública e (ii) a conta de juros no balanço de pagamentos passasse de uma posição deficitária de pouco mais do que US\$ 1 bilhão, no começo dos anos 1990, para uma média superior a US\$ 6 bilhões entre 1999 e 2003. No auge da fase "eufórica" do modelo, entre 1992 e 1998, a economia cresceu ao ritmo de 6\% ao ano, acumulando um déficit em transações correntes de mais de US\$ 60 bilhões, financiados por uma entrada líquida de capitais de cerca de US\$ 100 bilhões. Somente em investimento direto externo (valores brutos) o país captou US\$ 60 bilhões no mesmo período, quando da privatização de setores importantes como energia, petróleo e telecomunicações (IMF, 2004d).

A relação juros pagos/exportações deteriorou-se fortemente, passando de cerca de 30\%, entre 1991 e 1993, para mais de 40\% depois de 1999, o que explicita a fragilização financeira do padrão de financiamento externo do modelo argentino. É interessante notar que entre 1992 e 2000 a entrada líquida de capitais superou os déficits em transações correntes, e que o ajuste da conta corrente depois de 1999 se deu, em um primeiro momento, mais em função da forte contração dos gastos com importações do que pelo crescimento das exportações, o que só irá ocorrer de forma significativa a partir de 2003 (gráficos 4 a 6). Ademais, a grave recessão entre 1999 e 2002 não só eliminou os ganhos derivados da euforia do início da conversibilidade, como também agravou a situação fiscal do setor público, que teve de ampliar o endividamento para fazer frente à perda relativa de capacidade de arrecadação tributária. Entre 1993 e 2002, as rendas do setor público não financeiro cresceram $11 \%$ e as despesas, $32 \%$. Estas passaram a ter uma natureza cada vez mais financeira, já que a proporção do pagamento de juros sobre a dívida pública com respeito ao total das despesas passou de 7\% em 1993 para 18\% em 2001. Para se colocar em perspectiva, as despesas com pessoal caíram de $17 \%$ para $12 \%$ e o conjunto dos gastos de custeio da máquina pública passou de $28 \%$ para $16 \% .{ }^{10}$ É bom lembrar que, no mesmo período, a dívida pública argentina passou de cerca de $35 \%$ para $64 \%$ do PIB. Tal incremento deu-se quase que exclusivamente em títulos denominados em dólares. Assim, atrelou-se a fragilização fiscal à fragilização externa. 
Gráfico 4: Balança comercial da Argentina - 1980-2004 (US\$ milhões FOB)

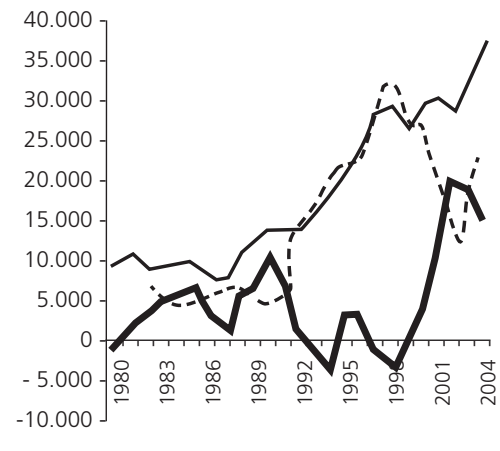

$\mathrm{X}_{-\ldots-\ldots .} \mathrm{M} \longleftarrow$ Saldo

Gráfico 5: Contas corrente e financeira do BP da Argentina 1992-2003 (US\$ milhões)

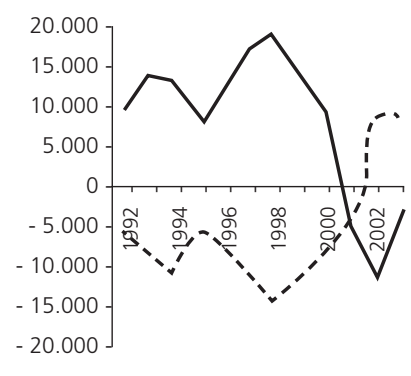

CC CF

Gráfico 6: Contas corrente e financeira da Argentina - 1992-2003 (\% PIB)

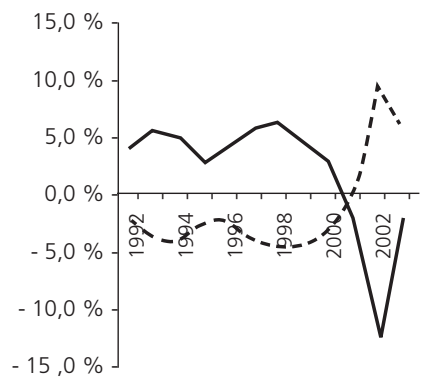


Com tal padrão de crescente endividamento externo e reduzida capacidade de pagamento, o país mostrou-se cada vez mais vulnerável aos choques externos - financeiros ou reais. O primeiro ataque especulativo ao peso ocorreu em 1992, tendo sido relativamente bem administrado com a elevação da taxa de juros e a venda de reservas oficiais. Porém, na "crise Tequila", em 1995, verificou-se um forte credit crunch, com os depósitos bancários caindo 18\% em média. Se, entre 1991 e 1994, a taxa média de crescimento do PIB foi de 8\%, com a recessão de 1995 a renda contraiu-se em 3\%. A taxa de desemprego urbana - que, com a liberalização econômica, já havia mudado de patamar, dos $4 \%$ em média da década de 1980 para os $8 \%$ da primeira metade dos anos 1990 - passa a crescer de forma exponencial, mesmo com a recuperação do triênio 1996-1998, atingindo mais de 15\% em média depois de 1999 (gráfico 1). Ainda assim, verificou-se uma rápida recuperação. É de se ressaltar que o governo tomou medidas fiscais mais apertadas no período, como o aumento do IVA de $18 \%$ para $21 \%$ e o corte nos salários do funcionalismo público, dentre outras medidas. Os ganhos fiscais atingiram cerca de $2 \%$ do PIB (IMF, 2004d).

Na segunda metade dos anos 1990, a Argentina teve de enfrentar uma seqüência de choques exógenos que foram colocando em xeque os fundamentos que davam sustentação à conversibilidade. A crise asiática em 1997, o default russo em 1998, a desvalorização do real em 1999, a queda nos preços das commodities agrícolas e minerais, em conjunto com a apreciação do dólar nos anos seguintes, amplificaram o cenário de baixa liquidez financeira externa e a redução na competitividade comercial. O governo recém-eleito de De la Rua trouxe, na sua fase final, novamente Domingo Cavallo para o centro das decisões econômicas. Criou-se uma imensa expectativa em torno do criador da conversibilidade, que obteve do Congresso a ampliação das atribuições de sua pasta com vistas a debelar a grave crise que já se instaurara. Suas tentativas de reativar a economia flexibilizando a política monetária e o arranjo cambial não se mostraram bem-sucedidas. ${ }^{11}$ A partir de 1999 o país mergulhou em uma profunda recessão. Em particular, o ano de 2001 foi marcado por uma crescente perda de confiança na solvência da economia argentina, especialmente do setor financeiro. As reservas internacionais, que no começo de 2001 estavam na casa dos US\$ 21 bilhões, caíram rapidamente para menos de US\$ 15 bilhões em agosto. Com o apoio do Fundo, 
verificou-se uma recomposição das reservas para os níveis do início do ano. Porém, com o agravamento da crise, chegou-se em dezembro com reservas abaixo de US $\$ 14$ bilhões. A queda dos depósitos bancários em quase 1/3 e os saldos negativos da conta capital, que chegaram a US\$ 6 bilhões no último trimestre, não deixavam dúvidas quando ao fato de que estava em curso uma grave crise de confiança marcada pela fuga de capitais.

No auge da instabilidade, no último bimestre do ano, a redução dos depósitos bancários se dava no ritmo de $\$ 500$ milhões por dia. Em dezembro, o peso e o governo desabam, diante da pressão das manifestações populares (os "panelaços"). Depois de uma rápida passagem de Rodriguez Saá — que decretou a suspensão dos pagamentos da dívida externa do setor público —, a Presidência passou ao senador Eduardo Duhalde — ex vice-presidente do primeiro governo Menem —, que teve de levar adiante a "pesificação" da economia, o que implicou a inconversibilidade dos ativos dolarizados do sistema financeiro, o chamado corralito. É interessante notar que, nos momentos mais agudos de crise, especialmente antes da queda final da conversibilidade, o FMI esforçou-se em liderar pacotes de socorro para o país, que era um dos seus casos exemplares de implementação de reformas liberalizantes. Entre 1991 e 2001, foram firmados cinco acordos (1991, 1992, 1996, 1998 e 200-2001), além de dois outros em 2003 — cujos recursos eram destinados fundamentalmente para honrar os compromissos já assumidos. Os montantes desembolsados pelo Fundo chegaram a US\$ 42 bilhões em valores correntes (ou DES 27 bilhões), dos quais US\$ 23 bilhões no acordo stand-by de 2000 e sua suplementação em 2001.

Um balanço das conseqüências econômicas e sociais desse período deve partir da constatação de que a Argentina passou, em pouco mais de uma década, de um país caracterizado por uma alta homogeneidade social para um novo perfil de concentração da renda mais próximo à realidade média latino-americana (tabela 1). Entre 1980 e 2002, o decil superior viu sua participação na renda passar de $31 \%$ para $41 \%$, ao passo que o decil inferior experimentou uma queda de $2,8 \%$ para $1,8 \%$. A principal contrapartida nessa mudança foi a queda nos decis intermediários, que perderam espaço equivalente a 10 pontos percentuais do PIB, caracterizando um achatamento na classe média, predominantemente urbana. Em 2002, o índice de Gini para a Argentina ${ }^{12}$ era de 0,590, bem acima dos 0,501 de 1990. Assim, o qua- 
dro distributivo argentino, no auge da crise e após mais de uma década de reformas liberalizantes, era pior do que o verificado em países como Bolívia, Colômbia, Equador, Paraguai, Peru, México e todos os países centro-americanos. No contexto latino-americano, a distribuição de renda da Argentina só não era pior que a do Brasil.

Mais que isso, a pobreza, que sempre foi um fenômeno marginal, tornou-se generalizada e, como se verá adiante, chegou a afetar metade da população. Em nossa concepção, esse fato alterou os parâmetros de comparação para a qualidade do desempenho econômico recente. Vale dizer, a atual recuperação do crescimento só pode ser apontada como um "sucesso" em comparação com a forte deterioração provocada pelos últimos anos da “conversibilidade". Por outro lado, tomando-se uma perspectiva de longo prazo, é possível afirmar que a Argentina, mesmo com a reestruturação da dívida, está (e estará) muito distante do seu próprio passado e das expectativas que esse havia criado no imaginário social e político do país (Prebisch, 1950, 1981; Ferrer, 1973, 1998).

As estimativas para $2004^{13}$ apontam que $60 \%$ dos assalariados — formais e informais - recebiam menos de \$700. Dado que a cesta básica calculada pelo Indec ${ }^{14}$ estava ao redor de $\$ 750$, percebe-se que uma parcela significativa da população não ganhava o suficiente para fazer frente aos gastos elementares para a manutenção de uma família padrão de quatro pessoas. No setor privado, 1/3 dos assalariados ganhavam entre \$ 501 e \$ 800 mensais, ao passo que, no decil superior, a renda média superava $\$ 2.000$, e no inferior estava abaixo de $\$ 300$. A cesta básica de referência para o cálculo da população indigente inclui, basicamente, itens alimentares, situando-se na casa dos \$340. A partir dessa referência, estima-se que aproximadamente 5 milhões de argentinos (15\% da população) vivem abaixo desse padrão. Para se ter uma noção da dinâmica de deterioração no quadro da pobreza, basta lembrar que em 1980 somente 7\% das famílias urbanas foram declaradas pobres pelos critérios da Cepal, ${ }^{15}$ que considera como ponto de corte a renda recebida inferior ao dobro do valor da cesta básica de alimentação. Já a indigência, que significa uma renda inferior ao valor da cesta básica de alimentos, era de 2\%. Em 2002 essas cifras subiram, de forma dramática, para, respectivamente, $45 \%$ e $21 \%$. 
Outro ponto relevante é a modificação da dinâmica dos salários reais e, portanto, do impacto da variação de preços na renda dos trabalhadores (gráficos 7 e 8). Entre a "crise Tequila" (1995) e o fim da conversibilidade, os salários reais estagnaram em meio a um processo recessivo e deflacionário. A redução da atividade econômica e o alto desemprego não criavam espaço para ganhos substantivos nos salários. A partir da saída da conversibilidade a dinâmica salarial foi outra. A deflação desapareceu, quando se toma o índice geral de preços, retornando-se a um processo inflacionário moderado. No começo de 2002, em especial, verificou-se o período mais intenso de aceleração de preços, em função da forte desvalorização cambial. Até o final de 2004, a inflação acumulada chegou à casa dos 50\%, ao passo que os salários nominais variaram pouco mais de $30 \%$. É bem verdade que desde

Gráfico 7: Rendimento médio real na Argentina - 1980-2003 (1995 = 100)

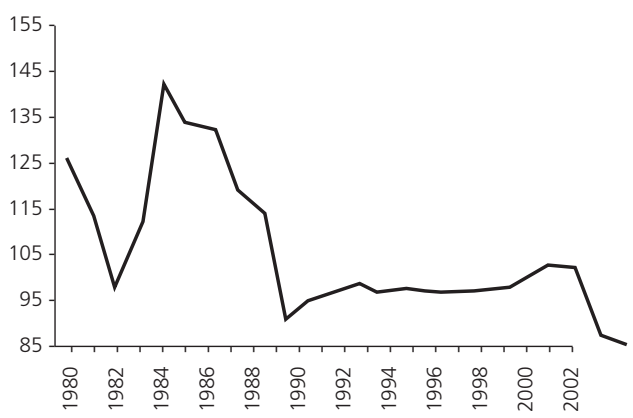

Gráfico 8: Índice geral de preços e rendimentos reais médios na Argentina 1995-2003 (1995 = 100)

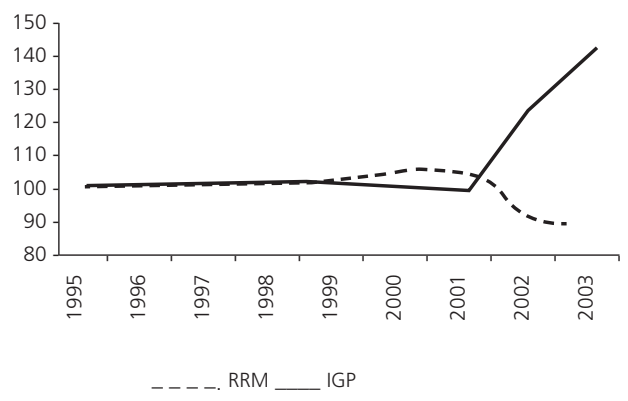

Fonte: Os dados de rendimento são da Base de Estadísticas e Indicadores Sociales da CEPAL (http://www.eclac.cl/badeinso/badeinso.asp). Os dados de preços são dos Informes Trimestrais de Conjuntura do Ministério da Economia (www.mecon.gov.ar). Dados capturados em março de 2005. Elaborado pelos autores. 
2004 os salários reais apresentaram uma tendência à recuperação, quando se compara em uma base anualizada. Porém, ainda não foi possível reverter as perdas acumuladas com a longa recessão e com a crise financeira de 2001-2002. É importante notar que, com a crise social que se instaura em 1999, os rendimentos reais do trabalho atingiram seus níveis mais baixos em 1/4 de século. Estimativas do Idesa apontam que, mantido o ritmo atual de crescimento dos salários reais, talvez demore ainda mais de cinco anos para que se recomponha o patamar de $1998 .^{16}$

Portanto, o governo Kirchner passou a enfrentar a questão da renegociação da dívida externa no contexto do que talvez seja a mais grave crise econômica e social enfrentada pelo país. Os indicadores destacados até aqui apontam, inequivocamente, para o impressionante fato de que a Argentina transformou-se, em pouco mais de uma década, em uma sociedade marcadamente desigual e com quase metade da população vivendo em condições muito próximas da pobreza ou indigência. Tal fato, que é a regra no continente latino-americano, emerge como uma importante exceção no caso da Argentina, cuja sociedade sempre foi relativamente mais homogênea que a média do continente, e onde problemas como desemprego e pobreza eram absolutamente marginais poucos anos atrás. A seguir analisamos o processo da reestruturação da dívida argentina, nos marcos mais gerais da instabilidade que vem marcando a inserção das economias periféricas na economia internacional.

\section{GLOBALIZAÇÃO FINANCEIRA, INSTABILIDADE E REESTRUTURAÇÃO DE DÍVIDAS SOBERANAS}

A crise financeira argentina não pode ser compreendida como um episódio isolado, derivado exclusivamente das opções domésticas de política econômica associadas ao Plano de Conversibilidade. Tampouco é um fenômeno inédito, quer na história do país, quer em uma perspectiva mais ampla, da inserção das economias periféricas na economia mundial. Os episódios de ampliação e contração da liquidez financeira internacional têm sido recorrentes, tal como os ciclos nos preços das commodities. Em ambos os casos, muitas economias periféricas são tragadas em ondas de euforia seguidas de depressão em função da ampliação/contração das condições de financia- 
mento externo e do padrão de distribuição do poder interno, o que condiciona a cristalização de modelos de crescimento baseados no consumo e no endividamento (Cepal, 2002, 2004). É esse o sentido da observação do Banco Mundial de que

(...) [as] ondas de capitais para os mercados emergentes têm sido, tipicamente, parte de um longo, periódico e rápido processo de expansão da economia global. Elas ocorrem quando uma ampla difusão de mudanças tecnológicas aprimora as comunicações e os transportes, o crescimento é animador, o comércio mundial está em expansão, as inovações financeiras são rápidas, e o clima político lhes dão sustentabilidade. (World Bank, 2000: 119, grifos no original)

Todavia, segue a análise,

[todos] os episódios passados de expansão dos fluxos de capitais para os mercados emergentes terminaram em severas crises internacionais. Hard landings, mais do que soft landings, têm sido a regra (...) Booms nos fluxos privados de capitais têm sido pontuados por freqüentes crises bancárias e cambiais nos países receptores, e terminado, usualmente, em severas rupturas econômicas e conflitos políticos. (idem, grifos no original)

O período que se seguiu à ruptura do Sistema de Bretton Woods foi marcado por pelo menos duas grandes ondas de expansão da liquidez financeira internacional seguida de crises financeiras. A primeira, na década de 1970, foi alimentada pela abundância de crédito bancário oriundo da reciclagem dos petrodólares. A elevação da taxa de juros norte-americana, a partir do final da década, criou o espaço para a emergência da crise da dívida externa na periferia. A segunda ocorreu nos anos 1990, no contexto da globalização financeira e, portanto, da desregulamentação e liberalização dos diversos mercados e do crescimento das finanças diretas. Dentre as regularidades empíricas que marcaram tais episódios, a literatura tem destacado a expansão do crédito doméstico associada à liberalização financeira (interna e externa), que estão na origem dos booms nos mercados reais e financeiros. Somam-se a apreciação da taxa de câmbio, a fragilização externa, com a deterioração dos saldos em conta corrente, e a redução na liquidez (ampliação da relação entre passivos e ativos externos e encurtamento das posições passivas), dentre outros fatores (IMF, 1998; Aziz et al., 2000). 
Depois do boom de afluxo de capitais privados para os mercados emergentes, entre a segunda metade dos anos 1980 e meados da década de 1990, a crise asiática (1997-1998) inaugurou uma fase de retração daqueles ${ }^{17}$ que só irá se encerar em 2003. O que poderia ser um episódio isolado mostrouse como um evento definidor de um novo momento. Depois da crise asiática o mundo foi abalado por uma série de crises financeiras que pareciam estar abalando a crença de que a globalização seria um processo virtuoso de espraiamento do progresso: a moratória russa e a falência de um importante fundo hedge norte-americano - o Long Term Capital Management — em 1998, a crise cambial brasileira em 1999 e as crises da Argentina e Turquia (2000-2002), além de uma série de episódios de menor visibilidade fora dos meios especializados, com destaque para a crise no pagamento dos Brady bonds do Equador, a instabilidade na Ucrânia, Paquistão e Venezuela, entre outras. Tais eventos deram margem a questionamentos sobre a capacidade dos arranjos institucionais vigentes de dar suporte ao processo de globalização, especialmente em sua dimensão financeira.

A crise argentina de 2002 é um típico episódio que reflete a natureza recente das relações entre os países periféricos e os mercados financeiros internacionais globalizados e desregulamentados. Isso porque foi baseada na quebra de vínculos contratuais entre um devedor soberano e milhares de investidores individuais, o que tornou extremamente complexo o processo de renegociação. Portanto, nos parece interessante ressaltar algumas das características principais das mudanças no padrão de intermediação financeira ao longo das últimas três décadas, explorando seus impactos sobre as relações entre devedores e credores, bem como sobre o papel de órgãos oficiais multilaterais como o FMI. Assim, antes da década de 1970, quando predominavam regimes de câmbio fixo, eram mais comuns crises de balanço de pagamentos (em conta corrente) onde se constatava uma inadequação das condições domésticas à sustentação do compromisso de se manterem taxas de câmbio. Políticas macroeconômicas que implicassem um nível de inflação muito superior à média internacional, ou choques nos termos de troca, sinalizariam para a possibilidade de rupturas. Normalmente, nos meses que antecediam tais crises, os principais leading indicators eram as políticas domésticas expansionistas e o crescimento (antecipatório de uma desvalorização) das importações com contração das exportações. A perda crescente de reservas internacionais anunciava a ruptura iminente. 
Os pacotes de socorro financeiro do FMI eram suficientes para normalizar as transações comerciais e de serviços, e vinham acompanhados de ajustes macroeconômicos que visavam adequar a absorção doméstica à capacidade de pagamentos externa.

O regime de câmbio flexível tornou-se dominante a partir de 1973, com o fim do compromisso de manutenção de taxas fixas entre as principais divisas internacionais. Todavia, não foi capaz de cumprir a promessa de que as flutuações na taxa de câmbio funcionariam como estabilizadores automáticos, garantindo, em simultâneo, o ajuste dos balanços de pagamentos e a liberdade para a adoção de políticas monetárias mais bem ajustadas à busca do equilíbrio doméstico. Do ponto de vista dos países em desenvolvimento, muitos dos quais mantendo suas moedas atreladas às divisas-chave, o problema central passou a ser a sustentabilidade dos passivos externos. $\mathrm{Na}$ década de 1990, a globalização financeira e a maior integração aos circuitos mais dinâmicos dos mercados de capitais tornaram a questão da conversibilidade da conta capital o calcanhar-de-aquiles dos países periféricos. O novo ciclo de endividamento modificou o perfil das dívidas, agora predominantemente junto a fontes privadas e com um elevado grau de pulverização.

Para Krueger (2003), os eventos dos anos 1990 levaram o FMI à necessidade de compreender melhor a natureza das crises da "conta capital". ${ }^{18}$ Quais seriam as suas especificidades? Em síntese, poder-se-ia dizer que: (i) elas podem ocorrer de forma mais rápida, na medida em que não dependem mais somente do volume de transações correntes mas, também, do estoque (e liquidez) dos instrumentos de dívida; (ii) estão sujeitas a um maior grau de subjetividade, pois ocorrem sempre que há uma perda de confiança dos investidores, o que nem sempre está associado à existência de problemas econômicos fundamentais; e (iii) com o predomínio das finanças diretas, os detentores de títulos de dívida que "legitimamente" têm motivos para desconfiar da sustentabilidade das políticas e instituições podem, rapidamente, acionar sinais de "venda" dos seus ativos. Além disso, a adoção generalizada entre os países emergentes de regimes cambiais mais rígidos abriu espaço para a emergência de crises de confiança quanto à manutenção da conversibilidade.

Com esse tipo de crise, segue Krueger (2003), o "tratamento" mais adequado seria a busca do resgate da confiança dos investidores na capacidade de cada país honrar os serviços de suas dívidas. Isso implicaria uma maior 
atenção à questão da gestão da dívida por parte de governos soberanos, mesmo aqueles capazes de adotar políticas macroeconômicas consideradas “saudáveis". Nesse sentido, o FMI estaria mais cético quanto aos benefícios de regimes de câmbio fixo (que induziriam ao agora perigoso sobre-endividamento em divisas) e mais ativo na indução de reformas estruturais associadas à regulação dos mercados financeiros e à adoção de arranjos institucionais mais transparentes (para a execução de políticas fiscal e monetária, na governança corporativa, em legislações de falência etc.). Tais elementos seriam centrais para a prevenção das crises. Já no caso de gerenciamento de crises, Krueger (2003) destaca que o Fundo ainda tem um papel importante a desempenhar, não só no que se refere à implementação de medidas corretivas e no aporte de recursos financeiros mas, sobretudo, na tentativa de coordenar os demais atores envolvidos nos processos de reestruturação de dívida. Aqui, coube um destaque especial ao estímulo à adoção de cláusulas de ação coletiva nos (novos) contratos de dívida soberana.

É interessante notar também que a literatura recente que procurou avaliar os impactos da liberalização financeira não foi capaz de encontrar vínculos sólidos entre aquela e o crescimento econômico. Em estudos realizados no âmbito do próprio FMI tem-se reforçado tal posição mais cautelosa quanto aos impactos potenciais dos fluxos de capitais nos países em desenvolvimento. Ao se relacionarem medidas de abertura financeira com indicadores de desenvolvimento econômico e dos mercados financeiros domésticos, constatou-se a existência de uma “(...) fraca relação entre crescimento e liberalização da conta capital e, como em outros estudos, dificuldade de encontrar relações significativas [entre crescimento e liberalização]"(IMF, 2001: 143). Por outro lado, identificou-se um efeito positivo sobre os investimentos e o desenvolvimento do setor financeiro. Os resultados do Fundo também apontaram para a existência de custos não desprezíveis associados à liberalização, em termos de aumento da instabilidade. A ampliação da liberalização da conta capital em muitos países em desenvolvimento teria vindo acompanhada de um aumento na volatilidade dos fluxos líquidos de capital e de redução no crescimento econômico.

Buscou-se a explicação para a fraca ligação entre crescimento e liberalização financeira nas falhas institucionais dos países receptores de capital. Quanto mais frágeis as instituições domésticas, especialmente de regulação 
dos mercados financeiros, maiores os custos potenciais da abertura em face dos benefícios potenciais. Na seqüência deste trabalho, dois estudos mais amplos (Edison et al. , 2002; Prasad et al., 2003) também não encontraram vínculos sólidos entre a liberalização financeira e o crescimento dos países em desenvolvimento. Em especial, Prasad et al. (2003) realizaram uma extensa revisão da literatura ${ }^{19}$ e um estudo sistemático de 76 países industrializados e em desenvolvimento para o período 1960-1999. Encontram divergências significativas entre as promessas dos modelos teóricos convencionais e a realidade alcançada pelos países em desenvolvimento.

A teoria apontaria diversos canais (diretos e indiretos) pelos quais a integração financeira poderia estimular o crescimento. Os fluxos de capitais teriam vários benefícios diretos. Ampliariam a poupança mobilizável pelos países em desenvolvimento e a taxa de retorno (ajustada ao risco) para os provedores do capital, os países industrializados. Permitiriam, ainda, a transferência de tecnologia, a pulverização do risco com resultados mais eficientes em termos de alocação de recursos e, por fim, o desenvolvimento dos mercados financeiros nos países receptores. Os efeitos indiretos estariam associados à promoção da especialização produtiva, via investimento direto externo, e à indução à adoção de políticas econômicas e instituições mais "saudáveis", na medida em que tais elementos passaram a ter um peso crescente na decisão de alocação de recursos dos investidores. Em conjunto, tais efeitos diretos e indiretos sustentariam a expectativa de que uma maior integração financeira poderia promover um maior crescimento.

Todavia, as evidências empíricas levantadas e a revisão da literatura sugerem uma conclusão distinta. Não foi possível provar a existência de um vínculo estreito entre abertura financeira e crescimento e, o que é pior, tal abertura geraria maior instabilidade doméstica:

(...) o exame sistemático das evidências sugere que é difícil estabelecer uma relação causal robusta entre o grau de integração financeira e o desempenho em termos de crescimento econômico. Na perspectiva da estabilidade macroeconômica, o consumo é tido como uma melhor medida do que o produto; então, flutuações no consumo são percebidas como tendo um impacto negativo no bem-estar econômico. Há pouca evidência de que a integração financeira tenha auxiliado os países em desenvolvimento a melhor estabilizar as flutuações no crescimento do consumo, em que pesem os amplos benefícios que, teoricamente, os países em desenvolvimento poderiam obter neste aspecto. (Prasad et al., 2003: 6) ${ }^{20}$ 
Portanto, a experiência argentina descrita anteriormente parece se enquadrar nos marcos mais gerais dos efeitos da liberalização sobre os países em desenvolvimento. No início, a euforia do reingresso nos mercados financeiros internacionais, onde se deu o encontro entre a liquidez externa abundante e a oferta doméstica de ativos - via privatizações e desregulamentação de mercados - em um país que havia se estabilizado e voltava a crescer de forma vigorosa. Entre 1991 e 1998, o PIB cresceu a uma taxa média próxima de 6\% e a inflação, que chegava a 30\% ao mês em 1991, estabilizou-se em um dígito ao ano. Porém, com o tempo foram se revelando o crescente endividamento e a rigidez de um modelo macroeconômico que minava a capacidade de se competir externamente em função da valorização cambial. Com a recorrência de crises financeiras, os mercados internacionais ficaram menos líquidos e mais receosos em aplicar seus recursos em países com elevada vulnerabilidade externa. Nesse novo quadro a Argentina passou a depender cada vez mais de recursos oficiais, dos pacotes financeiros liderados pelo FMI e de captações junto ao mercado privado de títulos de dívida portadores de juros suficientemente altos para contentar o apetite dos administradores dos fundos de investimentos mais agressivos em suas metas de rentabilidade. ${ }^{21}$ Com a moratória de 2001, restou a necessidade de se reestruturar uma dívida pulverizada de um país em convulsão social.

A revista The Economist ${ }^{22}$ descreveu o processo recente de reestruturação da dívida argentina como sendo "épico" em sua escala. Afinal, ele envolveu uma variedade de 152 títulos de dívida, que estavam denominados em seis moedas distintas e atrelados às jurisdições de oito países. Na ponta credora, cerca de 500 mil investidores, dos quais pouco mais de 75\% aceitaram a troca, gerando com isso um dos maiores deságios da história. Em fevereiro de 2005, a dívida elegível à reestruturação, incluindo os juros atrasados, era de US\$ 104 bilhões. Após o swap, ficou em US\$ 36 bilhões. Os três novos títulos emitidos apresentaram um valor de face equivalente a 35\% dos montantes originais. Mais importante ainda são os seus prazos de vencimento, que chegam a 42 anos. A profundidade do deságio só pode ser atenuada quando se leva em conta o fato de que, no auge da crise de 2002, o valor de mercado dos papéis da dívida argentina era ainda menor, cerca de 20\% do valor de face. Assim, estima The Economist, quem comprou tais papéis no final de 2002, com mais de um ano de default em curso, recebendo com a reestruturação um novo título com $35 \%$ do valor de face original, pôde 
auferir um ganho anualizado de $25 \%$. Isso revela pelo menos duas coisas: os investidores nos mercados secundários trabalhavam com um valor para a “dívida velha" que, ao longo da maior parte de 2002, era inferior à proposta do governo Kirchner; e assim, diante de tal avaliação, os ganhos de mercado não foram desprezíveis, por mais que os credores finais tenham experimentado uma perda de capital com respeito à suas expectativas originais.

A pressão dos credores por uma proposta mais alentadora deve ser racionalizada a partir de uma questão básica: a Argentina poderia pagar mais? Como se procurou evidenciar no item anterior, o quadro social e econômico herdado do período de conversibilidade e agravado com a crise financeira de 2002 gerou um conjunto de passivos de difícil equacionamento. Um deles, sem dúvida, é a dívida do setor público. Esta, mesmo com a reestruturação e o forte crescimento do PIB em 2003 e 2004, segue elevada, algo em torno de 75\% do PIB. Antes da reestruturação, a dívida estimada era de US $\$ 189$ bilhões. Depois passou a US\$ 121 bilhões. A dívida nova objeto da reestruturação representa somente $30 \%$ desse montante, ou seja, cerca de US $\$ 36$ bilhões, cujo valor original, incluindo principal e juros atrasados, era de US\$ 104 bilhões às vésperas do mega-swap. O restante se refere aos empréstimos obtidos junto ao FMI e outros órgãos multilaterais (US\$ 30 bilhões), ao estoque de títulos BODEN (US\$ 19 bilhões), que foram os bônus emitidos para compensar o setor financeiro pelas perdas associadas ao fim da conversibilidade ("a pesificação"), e a outros financiamentos e garantias, inclusive as vinculadas aos empréstimos realizados pelas províncias. ${ }^{23}$ A manutenção de uma elevada relação dívida/PIB projeta para o futuro uma considerável carga para o pagamento dos serviços da dívida. ${ }^{24}$ Alguns observadores ${ }^{25}$ ponderam que o esforço fiscal corrente, que aponta para um superávit primário de mais de $4 \%$ do PIB (o que exclui o pagamento de juros), já é mais do que razoável, em função do passivo social e da desestruturação econômica. Ademais, a recuperação em curso se dá em um contexto excepcionalmente favorável de crescimento da demanda mundial e de recuperação de preços de commodities que são importantes para a pauta exportadora do país - entre 1999 e 2003, os setores primários e a indústria processadora de produtos agrícolas responderam, em média, por 53\% das exportações, contra 30\% do setor manufatureiro restante e $17 \%$ de combustíveis e energia. ${ }^{26}$ Nada garante que o ritmo de crescimento superior a $8 \%$ 
vá se manter, o que implicaria uma menor capacidade de acumular reservas oficiais e gerar receitas tributárias adicionais.

É importante compreender que a conjuntura externa mostrou-se excepcionalmente favorável nos últimos dois anos. De um lado, há o crescimento sincronizado da economia mundial — de 5,1\% em 2004, segundo estimativas do FMI (IMF, 2005) — , taxa recorde desde 1976. No âmbito dos países em desenvolvimento, o crescimento estimado é ainda maior — cerca de 7,2\%, a taxa mais elevada em 30 anos —, associado ao dinamismo da Ásia, liderado pela China, o qual será acompanhado por maiores taxas de crescimento na América Latina e no Leste Europeu. Essas taxas excepcionais de crescimento têm como contrapartida a expansão, igualmente um recorde recente, do comércio mundial - que deve atingir 8,5\% em 2004, segundo a $\mathrm{OMC}^{27}$ ou mais de $8 \%$ em termos de volume (IMF, 2005). Essa situação inédita em mais de duas décadas constitui uma das dimensões do "choque externo benigno". A outra dimensão tem sido a alta dos preços das commodities, ${ }^{28}$ especialmente de produtos primários, industrializados de origem agropecuária e do setor de energia (petróleo e derivados), que em conjunto representam cerca de $70 \%$ da pauta exportadora de mercadorias da Argentina. Em 2003 essa alta foi generalizada, atingindo as mais diversas modalidades de commodities - alimentos, grãos, óleos, metais etc. Por conta disso, o índice de preços de exportação apurado pelo Ministério da Economia teve uma variação positiva de $10 \%$ que, em conjunto com a estabilidade no índice de importações, implicou uma melhoria nos termos de intercâmbio também de 10\%. Já em 2004 essas diversas categorias apresentaram desempenho distinto. A influência negativa da queda do preço da soja e derivados ${ }^{29}$ sobre os preços dos produtos exportados pela Argentina fez com que os termos de intercâmbio apresentassem uma piora a partir do segundo trimestre do ano. ${ }^{30}$ Portanto, uma avaliação da renegociação da dívida argentina não pode prescindir de uma contextualização tanto da realidade local como do cenário internacional, pois ambos a condicionaram.

\section{CONSIDERAÇÕES FINAIS: ALGUNS DESAFIOS DE AGORA EM DIANTE}

Duas frases do presidente Kirchner, ${ }^{31}$ expressas no calor do desfecho da reestruturação, parecem refletir bem o espírito então dominante na Argentina. Se, por um lado, afirmou o presidente, "começamos a sair da conjuntura 
para poder enxergar mais adiante", por outro, "o país não saiu do inferno". Procurou-se argumentar ao longo deste trabalho que o período de conversibilidade e reformas liberalizantes deixou por herança uma Argentina fragilizada, econômica e socialmente. A crise da dívida e sua posterior reestruturação são somente uma das diversas manifestações dos passivos acumulados. Contraditoriamente, a própria saída do default é tanto uma fonte de alívio quanto de problemas. Isso porque a Argentina deverá voltar a pagar uma dívida que não estava sendo honrada e que, por isso mesmo, deu algum fôlego para a recuperação recente. Não se deve esquecer que, ao normalizar suas relações com os credores, o país terá de honrar débitos da ordem de US $\$ 13$ bilhões em 2005, e algo próximo a isso em 2006. A partir de então serão mais US\$ 45 bilhões até 2010.

Em 2004 o superávit fiscal primário atingiu cerca de 4\% do PIB, um esforço superior aos 3\% negociados com o FMI. Para 2005, o Banco Central da Argentina projetou um crescimento de 5\%, ao passo que a proposta orçamentária do Ministério da Economia trabalha com uma expansão de 4\%, com uma inflação esperada entre 5\% e 8\%. Como metade da dívida em pesos está indexada à variação da inflação, cada ponto percentual de aumento no nível geral de preços amplia em \$ 1,5 bilhão os custos de carregamento da dívida consolidada em moeda doméstica. Projeta-se, igualmente, uma apreciação do peso em face do dólar. Se isso ocorrer, as rendas oriundas das exportações de bens agropecuários e seus derivados manufaturados poderá cair em pesos, o que poderá comprometer a arrecadação tributária projetada para o ano de 2005 - 60\% do seu incremento foi baseado na hipótese do crescimento daqueles setores. O primeiro trimestre de 2005 vem sendo marcado por significativas pressões inflacionárias e por confrontos entre o governo e grandes empresas em torno do tema das remarcações de preços.

Por conta disso, é importante se deixar marcado que a recente renegociação da dívida não eliminou a difícil situação na qual a Argentina se encontra, tanto do ponto de vista dos seus determinantes conjunturais quanto dos estruturais. Procuramos enfatizar também que há elementos para se considerar que a proposta argentina para seus credores foi mais do que razoável, na medida em que (i) implicou ganhos de capital quando se toma por base o valor da dívida nos mercados secundários no período que se seguiu ao default e (ii) colocou-se no limite superior da capacidade fiscal corren- 
te e (potencialmente) futura. Mais importante ainda tem sido o apoio que a sociedade está dando ao governo do presidente Kirchner e à posição do ministro da Economia, Roberto Lavagna. Emerge dessa nova situação, que circunstancialmente indica uma superação sobre a situação prévia de conflito entre sociedade e Estado, a possibilidade de se dar continuidade a uma mudança de modelo econômico e social. Avançou-se sobre os escombros do período da conversibilidade. Ainda assim, para que a Argentina realmente possa "começar a sair da conjuntura", como disse Kirchner, há que se iniciar o enfrentamento de pelo menos dois dilemas fundamentais.

Por um lado, a sociedade precisa reafirmar, ao longo dos próximos anos e décadas, seu compromisso com esse (aparente) novo caminho, que enfatiza a busca de um maior equilíbrio entre a estabilidade macroeconômica e o fortalecimento dos tecidos econômico e social, o que implica o restabelecimento de parâmetros mais homogêneos na distribuição de riqueza, renda e poder. Podemos chamá-lo de "via desenvolvimentista”, em contraposição ao período liberalizante da conversibilidade. Aquele ponto não é trivial, dado que a própria continuidade da conjuntura favorável pode estar ameaçada pelas incertezas tanto internas quanto do ambiente econômico internacional. Em especial, a determinação de seguir a via desenvolvimentista será recorrentemente testada diante das ondas dos ciclos financeiros, que convidam o país a retornar ao padrão de comportamento típico dos períodos de plata dulce, ou seja, de crescimento — vigoroso, porém de fôlego curto - liderado pelo consumo e financiado pelo endividamento externo. Essa tem sido a trajetória do país desde a liberalização econômica da segunda metade dos anos 1970. Ainda é cedo para se afirmar que a Argentina tenderá a assegurar o rumo desenvolvimentista contra a possibilidade das armadilhas que surgem com o excesso de liquidez internacional.

Por outro lado, também não está claro se o país saberá resolver a disparidade entre seu passado e seu presente. Vale dizer, se as exigências de parte da sociedade, em particular dos mais afetados pela crise social dos anos 1990, serão construídas a partir dos parâmetros históricos da Argentina "homogênea" ou se, depois da conversibilidade, surgiram novos parâmetros que balizam as expectativas e as pressões sociais. Isso nos leva à questão do tempo que o novo rumo que o presidente Kirchner parece querer implementar terá para fixar raízes na sociedade. Pressões prematuras e excessivas para as 
possibilidades presentes (mas não em termos históricos) podem abortar a tentativa de construção de um modelo desenvolvimentista. Mas, também, a aceitação das condições atuais como termo de comparação pode aniquilar a força social dos atores interessados na via desenvolvimentista.

Assim, a combinação das especulações anteriores sugere que os cenários futuros da Argentina - conjunturais e estruturais - dependem da capacidade política de quem irá liderar essa nova etapa e também de um consenso social mais robusto e duradouro, capaz de ancorar politicamente tais lideranças. Se isso ocorrer, não será uma novidade. Basta lembrar que o modelo de primazia do mercado sobre a sociedade foi amplamente respaldado no início dos anos 1990. Resta saber se, diante dos resultados negativos daquela escolha, a sociedade argentina terá força suficiente para inverter sua fórmula, assumindo novamente um maior poder de controle do seu destino. ${ }^{32}$

\section{NOTAS}

1. No final dos anos 1970 a Argentina experimentou um processo de liberalização econômica em um contexto de abundância de liquidez externa. A valorização cambial implicou perda de competitividade. Com a crise da dívida externa, o país enfrentou um forte ajuste recessivo e anos de inflação elevada (Ferrer, 1998).

2. Carlos Saúl Menem (1989-1995, 1995-1999), do partido Justicialista (popularmente conhecido como "Partido Peronista", em homenagem a Juan Domingo Perón, seu fundador), foi eleito para suceder Raúl Alfonsín (1983-1989), da tradicional União Cívica Radical. Alfonsín foi responsável pela transição democrática, porém teve seu mandato encurtado (e obscurecido) pelos surtos de hiperinflação. Originalmente associado a um discurso nacional-populista, Menem rapidamente alinhou-se ao Consenso de Washington, promovendo a estabilidade por meio do Plano de Conversibilidade, em 1991. Menem foi sucedido por De la Rua (1999-2001), que caiu em meio à crise financeira, sendo sucedido por Rodriguez Saá (2002), que não durou um mês no poder e, finalmente, por Eduardo Duhalde (2002-2003). O atual presidente, Néstor C. Kirchner, assumiu o poder em maio de 2003.

3. Ver, por exemplo, Strange (1986), World Bank (2000) e Cepal (2002).

4. A exposição original do CW pode ser encontrada em Williamson (1989). Uma avaliação crítica, após mais de uma década de reformas liberalizantes, está disponível em Rodrik (2003).

5. Todos os gráficos e tabelas estão em anexo.

6. A notação \$ refere-se a pesos argentinos em valores correntes.

7. A "Lei da Conversibilidade" foi aprovada no Congresso no dia 27/3/1991. Fixou-se o valor do dólar em 10 mil austrais e garantiu-se a plena conversibilidade da moeda. 
O novo peso entraria em circulação em janeiro de 2002, com a paridade de 1:1 com o dólar norte-americano (IMF, 2004d).

8. Entre 1980 e 1990, a formação bruta de capital como proporção do PIB foi, em média, de $20 \%$. Entre 1991 e 2002, tal relação caiu para 18\%. No melhor momento da economia argentina nos anos 1990, os investimentos chegaram a 20\%, ao passo que na década anterior eles atingiram até 24\% do PIB (Anuário Estatístico da Cepal, 2003 - www.eclc. cl, dados capturados em março de 2005).

9. Em dezembro de 1991, a dívida externa total da Argentina era de US\$ 62 bilhões, o que equivalia a 32\% do PIB ou 5,1 vezes o volume de exportações. Entre 1998 e 2001, a dívida ultrapassou a casa dos US\$ 140 bilhões, mais de 50\% do PIB, em média, ou quase seis vezes as exportações. Em sua estrutura, mostrou-se predominantemente pública — mais de $60 \%$ na média do período. Todavia, verificou-se uma participação crescente de tomadores privados, financeiros e não financeiros, que no começo dos anos 1990 respondiam por menos de 20\%, e no auge do endividamento, entre 1998 e 2002, representaram $40 \%$ do estoque de dívida (estimativas dos autores com base nos dados do Ministério da Economia - Informes Trimestrais de Conjuntura - tabelas do setor externo - www.mecon.gov.ar).

10. Tabela A6.1 (metodologia tradicional) de Finanças Públicas dos Informes Trimestrais de Conjuntura do Ministério da Economia (www.mecon.gov.ar). Dados capturados em março de 2005.

11. Cavallo procurou flexibilizar sua própria criatura de diversas formas. Alterou a âncora da conversibilidade do dólar para uma combinação do dólar com o euro. Procurou com isso escapar dos efeitos da apreciação do dólar em face do euro e, é claro, da rigidez do seu próprio regime cambial. Implementou-se uma "política de competitividade" que se traduziu em isenções tributárias para os setores mais atingidos pela recessão. E, por fim, alongou-se o perfil da dívida pública com a realização do que na época se denominou um "mega-swap", que envolveu a troca de títulos públicos no valor de \$ 30 bilhões por papéis mais longos - reduziu-se o valor de face dos títulos em quase \$ 1 bilhão, ampliou-se o prazo médio de vencimento em quatro anos e reduziu-se a taxa implícita de desconto em $3 \%$. Medidas no plano fiscal visavam ao equilíbrio das contas públicas (IMF, 2004b, 2004c, 2004d).

12. Quadro 265 do Anexo Estatístico do "Panorama social de América Latina 2004" da Cepal. Os dados que utilizam o índice de Theil apontam no mesmo sentido. Informações capturadas em março de 2005.

13. Informações capturadas em março de 2005 no site do Ministério da Economia da Argentina - www.mecon.gov.ar.

14. Instituto Nacional de Estadísticas y Censos (www.indec.gov.ar).

15. Anuário Estatístico da Cepal, 2003 - disponibilizado em www.eclac.cl, dados capturados em março de 2005 - e quadro 15 do Anexo Estatístico do "Panorama Social de América Latina 2004" da Cepal. 
16. Instituto para el Desarrollo Social Argentino (www.idesa.org): "La inflación golpea mas a los pobres" - Informe Semanal 13/3/05; e "Se puede evitar el fracaso de las negociaciones salariales" - Informe Semanal 6/3/05.

17. A entrada líquida de capital privado nos países em desenvolvimento atingiu seu auge em 1996 com o montante equivalente a 3,5\% do PIB conjunto desses países. A partir da crise asiática, esse indicador caiu para níveis tão baixos quanto os verificados no período da crise da dívida dos anos 1980. Cálculos a partir da base de dados do FMI (www.imf.org) - World Economic Outlook, outubro de 2001.

18. Essa "confissão" reforça as críticas externas, pela "direita" e a "esquerda", de que o FMI não estaria diagnosticando e tratando adequadamente as crises dos anos 1990. Ver Meltzer (2000) e Stiglitz (2002), para citar dois exemplos notórios.

19. Os autores destacam que dos 14 estudos mais recentes que procuraram avaliar as ligações entre liberalização financeira e crescimento, e que utilizaram os mais variados métodos estatísticos, somente três sinalizaram alguma relação positiva. Em seu próprio estudo, Prasad et al. (2003) procuram associar indicadores de abertura financeira (estoques de ativos e passivos financeiros com respeito à renda) com indicadores de crescimento, utilizando diversas variáveis de controle usuais em estudos de crescimento econômico (escolaridade, qualidade das instituições, nível inicial de renda, etc.). Em todas as regressões os resultados foram considerados decepcionantes.

20. Em síntese, “(...) enquanto não há provas nos dados de que a globalização financeira tenha beneficiado o crescimento, há evidências de que alguns países possam ter experimentado como resultado uma maior volatilidade do consumo" (Prasad et al., 2003: 6).

21. O FMI enfatizou a inconsistência da política fiscal e a rigidez do regime cambial como causas da crise: "A crise resultou da falha dos policymakers argentinos em tomar, com antecedência, as medidas corretivas necessárias, particularmente no que se refere à consistência da política fiscal e à escolha do regime cambial.” (IMF, 2004d: 10 — tradução livre dos autores). É importante lembrar que o FMI apoiou sistematicamente o regime de conversibilidade e tomou o país como caso exemplar por muitos anos.

22. "A victory by default?", The Economist, 3 de março de 2005.

23. "A victory by default?", The Economist, 3 de março de 2005, $\operatorname{IMF}(2004,2004$ b).

24. Cujo cupom cambial está entre $2 \%$ e $5 \%$ nos primeiros dez anos, contra os cerca de $10 \%$ dos papéis soberanos emitidos pelo Brasil. “A victory by default?", The Economist, 3 de março de 2005.

25. "A victory by default?", The Economist, 3 de março de 2005; "Has Argentina changed the rules of the sovereign debt game?”, Blog de Brad Setser' em 26 de fevereiro de 2005 (capturado em março de 2005 no site: http://www.roubiniglobal.com/setser/); “The Successful End of Argentina's Debt Restructuring Saga”, Nouriel Roubini Global Economics Blog, 2 de março de 2005 (http://www.stern.nyu.edu/globalmacro/countries/argentina. html).

26. Estimativas dos autores com base nos dados do Ministério da Economia (www.mecon. gov.ar) - tabela A 5.2 dos dados do setor externo dos Informes Trimestrais de Conjuntura (dados capturados em março de 2005). 
27. “2004 trade growth to exceed 2003 despite higher oil prices", Press/386, 25 October 2004. Capturado em dezembro de 2004 em http://www.wto.org/english/news_e/pres04_e/ pr386_e.htm.

28. Entre 2001 e 2003, o preço da soja e derivados cresceu mais de 50\%; em 2004 verificouse uma tendência de queda. Já as commodities metálicas, cujos preços ampliaram-se em cerca de 10\% naquele período, atingiram um crescimento de 20\% em 2004 (Unctad, 2004 e The Economist, diversos números). Tal alta esteve associada a três principais determinantes, que se auto-reforçaram: a retomada da economia mundial, as características do crescimento chinês (altas taxas e investimentos em novas plantas) e compras especulativas por parte de fundos de investimento, fomentadas pela combinação particular dos preços-chave da economia mundial (taxas de juros baixas e desvalorização do dólar).

29. A queda de quase 40\% (em dólares) decorreu, principalmente, das melhores condições previstas para as próximas safras nos três principais produtores mundiais, Estados Unidos, Brasil e Argentina (Unctad, 2004, The Economist, diversos números).

30. Tabela A4.16 dos indicadores de preços — Informes Trimestrais de Conjuntura do Ministério da Economia (www.mecon.gov.ar). Dados capturados em março de 2005.

31. "Cambio de pantalla y Argentina sigue en juego". Capturado em março de 2005 no website do jornal Página 12: http://www.pagina12web.com.ar/diario/elpais/1-48044.html. Livremente traduzido pelos autores.

32. Nunca é demais lembrar que tal "poder" é sempre relativo, ainda mais em tempos de globalização econômica, quando os Estados devem mediar interesses que podem estar muito além de suas capacidades.

\section{REFERÊNCIAS BIBLIOGRÁFICAS}

AZIZ, J., CARAMAZZA, F., SALGADO, R. (2000) “Currency Crises”. In: Search of Common Elements. IMF Working Paper, WP/00/67. Washington, DC: International Monetary Fund.

CALVO, G. A., TALVI, E. (2005) "Sudden Stop, Financial Factors and Economic Collpase in Latin America: Learning from Argentina and Chile”. NBER Working Paper n. 11.153. Cambridge, Mass.: National Bureau of Economic Research.

CARrerA, J. (2005) (s.d). "Hard Pegs and Monetary Unions: main lessons of the argentine experience”. Disponível em http://www.stern.nyu.edu/globalmacro/countries/argentina. html (capturado em fevereiro).

CEPAL (2002) "Growth with Stability: financing for development in the new international context”. Santiago, Chile: Comissión Económica para America Latina y Caribe.

(2004) “Desarrollo Productivo en Economías Abiertas". Santiago, Chile: Comissión para America Latina y Caribe.

DOOLEY, M. P., FOLKERTS-LANDAU, D., GARBER, P. (2003) “An Essay on the Revived Bretton Woods System”. NBER Working Paper n. 9.971. Cambridge, Mass.: National Bureau of Economic Research. 
(2004) "The Revived Bretton Woods System: the effects of periphery intervention and reserve management on interest rates and exchange rates in center countries". NBER Working Paper n. 10.332. Cambridge, Mass.: National Bureau of Economic Research.

EATWELL, J., TAYLOR, L. (2000) “Global Finance at Risk”. Nova York: The New Press.

EDISON, H., KLEIN, M., RICCI, L., SLOK, T. (2002) “Capital Account Liberalization and Economic Performance: a review of the literature”. IMF Working Paper 02/120. Washington, DC: International Monetary Fund.

EDWARDS, S. (1995) “Capital Controls, Exchange Rate and Monetary Policy in the World Economy”. Cambridge, MA: Cambridge University Press.

FERRER, A. (1973) "La Economia Argentina: Las Etapas de su Desarrollo y Problemas Actuales”. Buenos Aires: Fondo de Cultura Económica.

_ (1998) “El Capitalismo Argentino”. Buenos Aires: Fondo de Cultura Económica.

GOLDSTEIN, M. (2001) "An Evaluation on Proposals to Reform on International Financial Architecture”. NBER Conference on Management of Currency Crises.

IMF (1998) World Economic Outlook, May. Washington, DC: International Monetary Fund

— (2001) World Economic Outlook, October. Washington, DC: International Monetary Fund

_ (2004) "First Review of the Stand-by Arrangement". IMF Country Report n. 04/194 (Argentine). Washington, DC: International Monetary Fund.

— (2004b) “Second Review of the Stand-by Arrangement”. IMF Country Report n. 04/195 (Argentine). Washington, DC: International Monetary Fund.

— (2004c) World Economic Outlook, October. Washington, DC: International Monetary Fund.

— (2004d) The IMF and Argentina, 1991-2001. Washington, DC: International Monetary Fund.

— (2005) World Economic Outlook, May. Washington, DC: International Monetary Fund.

KRUEGER, A. O. (2001) "International Financial Architecture for 2002: A New Approach to Sovereign Debt Restructuring”. Speech at the National Economists' Club Annual Members' Dinner American Enterprise Institute, Washington DC.

_ (2003) "Detecting and Preventing Financial Crises - Recent IMF Approaches". Speech at the Bretton Woods Committee Annual Meeting U.S. State Department.

MELTZER, A. H. (2000 - Chairman) Report of the International Financial Institution Advisory Commission. Washington, DC: International Financial Institution Advisory Commission.

MUNDELL, R. (2000) "Currency areas, exchange rate systems and international monetary reform”, Journal of Applied Economics, November III (2), p. 217-256.

PRASAD, E., ROGOFF, K., WEI, S., KOSE, M. A. (2003) "Effects of Financial Globalization on Developing Countries: Some Empirical Evidence”. 
PREBISCH, R. (1950) The Economic Development of Latin America an Its Principals Problems. Nova York: United Nations.

— (1981) Capitalismo Periférico: Crisis e Transformación. México: Fondo de Cultura Económica.

RODRIK, D. (1998) “Who Needs Capital-Account Convertibility?”. Disponível em http://ksghome.harvard.edu/ .drodrik.academic.ksg/papers.html.

— (2003) “Growth Strategies”. Disponível em http://ksghome.harvard.edu/ .drodrik.academic.ksg/papers.html.

STIGLITZ, J. E. (2002) A globalização e seus malefícios. São Paulo: Futura.

STRANGE, S. (1986) Casino Capitalism. Blackwell Publishers.

WILLIAMSON, J. (1990) "What Washington Means by Policy Reform”. In: J. Williamson (ed.), Latin American Adjustment: How Much Has Happened? Washington, DC: Institute for International Economics.

- (1995) "What Role for Currency Boards?", Policy Analyses in International Economics, 40. Washington, DC: Institute for International Economics.

WORLD BANK (2000) Global Development Finance, 2000. Washington, DC: World Bank. 